\title{
Quadro pronominal e colocação dos pronomes à luz de cinco gramáticas do português brasileiro
}

\begin{abstract}
Caroline Ozório Wink*
Letícia Finkenauer

Gabriel de Ávila Othero ${ }^{\oplus}$

Resumo: Investigamos o atual quadro pronominal em português brasileiro (PB), bem como as regras que essa variedade do português segue para colocação pronominal no caso de pronomes que ocupam a posição de objeto do verbo. Como ponto de início à nossa pesquisa, buscamos cinco gramáticas, relativamente recentes, que analisam os dados do $\mathrm{PB}$ no que se refere ao uso dos pronomes. Sistematizamos, neste artigo, as informações e análises dessas cinco gramáticas do $\mathrm{PB}$, a fim de auxiliar futuros pesquisadores que pretendam se debruçar sobre o tema e, assim, estender o trabalho de Fonseca (2008), de caráter semelhante.

Palavras-chave: gramática; pronomes; colocação pronominal; português brasileiro.
\end{abstract}

\begin{abstract}
We investigate the current pronoun system in Brazilian Portuguese (BP) and the word order rules that this variety of Portuguese follows in the case of pronouns occupying the object position of the verb. As a starting point for our research, we consulted five relatively recent $\mathrm{BP}$ grammars with respect to the use of pronouns and their word order. This article tries to systematize the information and analysis of these five BP grammars, in order to help future researchers who want research the issue and, also, in order to extend the work of Fonseca (2008), who also researches the use of pronouns in Portuguese grammars.
\end{abstract}

Keywords: grammar, pronouns, pronoun order, Brazilian Portuguese.

\section{Introdução}

Em nosso trabalho, pesquisamos cinco gramáticas relativamente recentes do português que levaram em conta os dados do português brasileiro (PB). Nosso objetivo central é sistematizar o que cada gramática traz a respeito dos pronomes pessoais, sobretudo sobre quais são os pronomes que ocupam a posição de sujeito de orações principais, quais são os pronomes que ocupam a posição de complemento nãopreposicionado do verbo e quais são as regras que o PB segue para a colocação

\footnotetext{
${ }^{*}$ Graduanda em Letras pela Universidade Federal do Rio Grande do Sul. Bolsista de iniciação científica na área de Teoria e Análise Linguística.

- Graduanda em Letras pela Universidade Federal do Rio Grande do Sul. Bolsista de iniciação científica na área de Teoria e Análise Linguística.

${ }^{\oplus}$ Professor Adjunto do Instituto de Letras da Universidade Federal do Rio Grande do Sul - UFRGS.
} 
pronominal em lexias verbais simples. Pretendemos, em trabalhos futuros, propor o quadro de pronomes que ocupam atualmente a posição de sujeito e complemento do verbo em PB, além de descrever as regras de colocação pronominal que o PB segue ${ }^{1}$. Como primeiro passo para esse objetivo ulterior, decidimos, portanto, investigar o que algumas gramáticas que tomam por base o PB dizem acerca do assunto. Partimos do texto de Fonseca (2008), que analisou as regras de colocação pronominal em lexias verbais simples propostas por três gramáticas de cunho normativo-tradicional (Bechara 2005, Cunha \& Cintra 2005 e Rocha Lima 2006). Ao contrário de Fonseca (2008), dirigimos nossa atenção também à relação de pronomes pessoais que cada gramática apresenta.

Em suma, este artigo trata da nossa revisão de literatura em gramáticas de cunho normativo ou descritivo sobre o quadro de pronomes e as regras de colocação pronominal específicos do PB. Esta revisão de literatura mostra-se oportuna uma vez que a organização do quadro pronominal e, primordialmente, a colocação dos pronomes objetos em lexias verbais simples está mostrando uma diferença na sintaxe e na prosódia das gramáticas do $\mathrm{PB}$ e do português europeu $(\mathrm{PE})^{2}$.

A seguir, passaremos à descrição dos apontamentos sobre os pronomes que iremos investigar nas cinco gramáticas pesquisadas.

\section{Pronomes e colocação pronominal em PB}

Escolhemos as seguintes gramáticas para verificar as regras relativas à colocação pronominal e o quadro de pronomes em PB: Moura Neves (2000), Luft (2002), Azeredo (2008), Castilho (2010) e Perini (2010). A maioria foi publicada nos últimos anos ou teve edições publicadas recentemente ${ }^{3}$ e todas consideram o português usado no Brasil, em sua variedade falada ou escrita, como veremos. Nas seções que seguem, descrevemos cada gramática com algum detalhe e apresentamos de forma isenta o quadro de pronomes, além das regras de colocação pronominal, que cada autor traz.

\footnotetext{
${ }^{1}$ Prévias de nossa proposta já foram apresentadas em Othero, Finkenauer \& Wink (2011).

${ }^{2}$ A respeito desse assunto, recomendamos a leitura de Vieira (2002, 2003).

${ }^{3}$ As gramáticas mais recentes de nossa lista tiveram sua primeira edição publicada em 2010 (Castilho 2010 e Perini 2010); a única gramática que não pode ser considerada "recente" é Luft (2002), cuja primeira edição é de 1974.
} 


\section{Moura Neves (2000)}

A Gramática de usos do português, de Maria Helena de Moura Neves, é uma gramática de orientação funcionalista, que pretende descrever os fenômenos gramaticais do PB com base em um corpus de língua escrita, armazenado no Centro de Estudos Lexicográficos da UNESP de Araraquara. O corpus contém "textos escritos de literaturas romanesca, técnica, oratória, jornalística e dramática" (NEVES, 2000, p.14). Apesar de seu caráter funcionalista, também encontramos orientações de natureza normativa nos pontos estudados, o que é atestado pela própria autora já na introdução da gramática:

Embora uma gramática de usos não seja, em princípio, normativa, para maior utilidade ao consulente comum a norma de usos é invocada comparativamente, de modo a informar sobre as restrições que tradicionalmente se fazem a determinados usos atestados e vivos. (NEVES, 2000, p.14)

Moura Neves (2000) apresenta a seguinte proposta para o quadro pronominal do PB:

\begin{tabular}{|l|l|l|}
\hline & Singular & Plural \\
\hline $1^{\circ}$ pessoa & Eu & Nós \\
\hline $2^{\circ}$ pessoa & Tu, Você & Vós, Vocês \\
\hline $3^{\circ}$ pessoa & Ele, Ela & Eles, Elas \\
\hline
\end{tabular}

Quadro 1: Pronomes pessoais retos em Moura Neves (2000)

Segundo a autora, as formas listadas acima ocorrem como sujeito do verbo. Além dessas, existem outras formas que não exercem essa função. São elas: 
a) formas átonas

\begin{tabular}{|c|c|c|c|c|}
\hline & \multicolumn{2}{|l|}{ Singular } & \multicolumn{2}{|l|}{ Plural } \\
\hline $1^{\circ}$ pessoa & \multicolumn{2}{|l|}{ me $(*)$} & \multicolumn{2}{|l|}{$\operatorname{nos}(*)$} \\
\hline $2^{\circ}$ pessoa & \multicolumn{2}{|l|}{ te $(*)$} & \multicolumn{2}{|l|}{$\operatorname{vos}(*)$} \\
\hline $3^{\circ}$ pessoa & $\mathrm{o}, \mathrm{a}$, lhe $(* * *)$ & $\operatorname{se}(* *)$ & os, as, lhes $(* * *)$ & $\operatorname{se}(* *)$ \\
\hline
\end{tabular}

Quadro 2: Pronomes pessoais oblíquos átonos em Moura Neves (2000)

* formas reflexivas ou não-reflexivas

** formas reflexivas

*** formas não-reflexivas

b) formas tônicas

\begin{tabular}{|c|l|l|}
\hline & Singular & Plural \\
\hline $1^{\circ}$ pessoa & Mim, comigo $\left(^{*}\right)$ & Nós, conosco $\left(^{*}\right)$ \\
\hline $2^{\circ}$ pessoa & Ti, contigo $(*)$ & Vós, convosco $\left(^{*}\right)$ \\
\hline $3^{\circ}$ pessoa & Si, consigo $(* *)$ & Si, consigo $\left.*^{* *}\right)$ \\
\hline
\end{tabular}

Quadro 3: Pronomes pessoais oblíquos tônicos em Moura Neves (2000)

* formas reflexivas ou não-reflexivas

** formas reflexivas

Moura Neves (2000) aponta, ainda, restrições de uso dos pronomes, como as formas $e u$ e $t u$, restritas à posição de sujeito; e as formas oblíquas átonas, que têm apenas funções completivas. Entretanto, para a autora, há construções em que as formas átonas podem ocorrer como sujeito, como em: "Deixe-me falar-lhe de minha felicidade" (NEVES, 2000, p. 453) [grifos da autora]. Outra observação interessante é que o pronome lhe, que funciona somente como objeto indireto do verbo na norma culta, pode assumir a posição de objeto direto do verbo. É o caso do exemplo "Nunca lhe vi desse jeito. Que foi, afinal?" (NEVES, 2000, p. 454) [grifos da autora].

Moura Neves (2000) observa o funcionamento das formas ele, nós e vós como sujeito e complemento do verbo, ressaltando o fato de a gramática normativa apenas aceitar a ocorrência como complemento quando as formas são preposicionadas ${ }^{4}$.

\footnotetext{
${ }^{4}$ Além disso, a autora também registra o uso da forma a gente como pronome pessoal na linguagem coloquial.
} 
A autora também assinala a função do pronome eu como referência genérica, isto é, "pode-se pensar em um enunciado em que o falante imagine o que qualquer pessoa pode vir a fazer, ou o que pode acontecer em um determinado lugar, e construa um enunciado de atribuição genérica colocando-se como sujeito do enunciado" (NEVES, 2000, p 463).

Em relação às regras de colocação pronominal, Moura Neves (2000) aborda as ocorrências da próclise, ênclise e mesóclise em textos.

\section{Luft (1987)}

A Moderna gramática brasileira, de Celso Pedro Luft, é uma gramática normativa que considera a norma culta utilizada no Brasil. Esse detalhe é importante no estudo dos pronomes, uma vez que a colocação pronominal é um ponto no qual as gramáticas do português brasileiro e europeu se distanciam marcadamente, como reconhece o próprio Luft (1987) em seu Prefácio:

Dei-lhe o nome de Moderna Gramática Brasileira, por tudo o que deve à Linguística moderna e porque na observação dos fatos idiomáticos me baseei no modelo (norma) brasileiro da língua portuguesa (cf., por ex., a colocação dos pronomes) (LUFT, 1987, p. 14).

Entretanto, ao contrário de encontrar uma análise diferenciada das gramáticas normativas tradicionais que baseiam as seções destinadas à colocação pronominal num uso não registrado na fala culta brasileira, Luft (1987) se atém a repetir a tradição gramatical nesse ponto. Abaixo, por exemplo, sistematizamos a relação de pronomes pessoais apresentada por Luft $(1987)^{5}$ :

Pronomes pessoais retos (funcionamento como sujeito ou como predicativo do sujeito):

$$
\begin{aligned}
& 1^{\text {a }} \text { pessoa: eu, nós } \\
& 2^{\text {a }} \text { pessoa direta: } t u \text {, vós } \\
& 2^{\text {a }} \text { pessoa indireta: você, vocês, vossa senhoria, etc. } \\
& 3^{\text {a }} \text { pessoa: ele, ela, eles, elas }
\end{aligned}
$$

${ }^{5}$ Essa sistematização encontra-se nas páginas 116 e 117 de Luft (1987). 
Pronomes pessoais oblíquos (funcionam como complemento de verbo):

a) Pronomes átonos:

$1^{\mathrm{a}}$ pessoa: me, nos

$2^{\mathrm{a}}$ pessoa direta: $t e$, vos

$2^{\text {a }}$ pessoa indireta: $o$, the, os, thes

$3^{\text {a }}$ pessoa: $o$, lhe, os, lhes

b) Pronomes tônicos:

$1^{\text {a }}$ pessoa: mim, comigo, conosco

$2^{\text {a }}$ pessoa direta: $t$, contigo, convosco

Pronomes reflexivos ("ação do verbo recai sobre o sujeito", p. 116):

a) Pronomes átonos:

$1^{a}$ pessoa: me, nos

$2^{\mathrm{a}}$ pessoa: te, vos,

$2^{\mathrm{a}}$ pessoa indireta: se

$3^{\mathrm{a}}$ pessoa: se

b) Pronomes tônicos (preposicionados):

$1^{\text {a }}$ pessoa: mim, comigo, conosco

$2^{\text {a }}$ pessoa direta: $t i$, contigo, convosco

$2^{\mathrm{a}}$ pessoa indireta e $3^{\mathrm{a}}$ pessoa: si, consigo

Sobre as regras de colocação pronominal, encontramos a observação de que a regra geral de colocação pronominal em PB é a ênclise, na qual o pronome se incorpora ao verbo que o precede. A colocação proclítica, para Luft (1987), é condicionada por “elementos de atração” (LUFT, 1987, p. 19), como as partículas QU e as negações. Porém, o gramático não exclui que a próclise seja um dos traços que "procuram evocar fala ou imprimir um tom coloquial, intimista, ou descontraído. Por contraste, a ênclise soa à cerimônia, linguagem objetiva, técnica, etc. (v.1)” (LUFT, 1987, p. 39). Em 
resumo, ainda que Luft (1987) pareça reconhecer a tendência proclítica do PB, o autor segue um padrão normativo de descrição pronominal.

\section{Azeredo (2008)}

A Gramática Houaiss da língua portuguesa, de José Carlos de Azeredo, pretende ter um caráter descritivo sem abster-se da normatização. Assim como as demais gramáticas analisadas neste artigo, esta também se debruça sobre os dados do português do Brasil. De acordo com o gramático,

O objeto desta gramática é a variedade padrão escrita do português em uso no Brasil. Identificamos assim um conjunto sistemático de formas e construções da língua portuguesa empregadas razoavelmente em comum por escritores/ jornalistas/ autores brasileiros, desde a segunda metade do século XIX até os dias atuais, em obras literárias, técnicas, científicas e ensaísticas em geral, assim como na maior parte dos textos impressos nos principais jornais e revistas dos grandes centros urbanos contemporâneos. (AZEREDO, 2008, p. 26)

Para Azeredo (2008), o sistema pronominal do português, no que se refere às funções de sujeito e complemento do verbo, organiza-se em pronomes pessoais retos e pronomes pessoais oblíquos, átonos ou tônicos. Dessa forma, temos a seguinte sistematização:

a) Pronomes retos: eu, tu, você, ele/ela, nós, vós, vocês, eles/elas.

b) Pronomes oblíquos átonos: me, te, o/a, lhe, se, nos vos, os/as, lhes.

c) Pronomes oblíquos tônicos: mim, ti, si, ele/ela, comigo, contigo, consigo, nós, conosco, vós, convosco, eles/elas.

Servem às funções de sujeito e de predicativo, as formas do grupo "a"; as formas do grupo "b" funcionam como complementos verbais; no grupo "c", por sua vez, estão as formas que servem às funções de complemento precedido de preposição.

Contudo, Azeredo (2008) admite que, em PB, as formas lhe/lhes assumem também a função acusativa, isto é, de objeto direto, indicando o interlocutor você/vocês, como em não the conheço, que corresponde a não conheço você. Tal emprego revela 
uma opção estrutural pela simetria, visto que o the forma ao lado de me, te e se um conjunto foneticamente harmônico.

Já as formas ele/ela/eles/elas/nós/vós podem funcionar, no "registro informal" (AZEREDO, 2000: 256), como objeto direto: "Mesmo os falantes mais escolarizados tendem a substituir as formas oblíquas átonas o/a/os/as por ele/ela/eles/elas, quando relativas à pessoa de quem se fala" (AZEREDO, 2008: 259).

Azeredo (2008) também observa que o uso de vós, bem como de suas formas verbais e possessivas correspondentes, é restrito e ritualizado. $\mathrm{O}$ pronome você, conforme Azeredo (2008), é a forma pronominal característica da interlocução coloquial na maior parte do território brasileiro. Em alguns estados do Nordeste e do Sul, prevalece o $t u$. Em algumas regiões, $t u$ ocorre em par com você, combinado sempre com o verbo na terceira pessoa. Essa forma pronominal (isto é, você) pode ser empregada em todas as posições sintáticas, assim como seu plural vocês. Para o autor, essa versatilidade reduz drasticamente a frequência das formas oblíquas átonas correspondentes.

Em se tratando de regras de colocação pronominal, Azeredo (2008) condicionase por fatores de três ordens: prosódica, sócio-comunicativa e sintática.

Sobre os fatores prosódicos, é necessário considerar duas variáveis:

a) O padrão que determina a distribuição dos acentos de intensidade; e

b) A colocação de modo que os vocábulos átonos se subordinem aos que contém sílaba tônica para a formação de vocábulos fonológicos:

A posição proclítica em que ordinariamente são colocados [os pronomes oblíquos átonos em $\mathrm{PB}$ ] favorece o relevo fonológico desses pronomes, tornando-os semitônicos. Nas frases coloquiais $\mathrm{Me}$ larga, Te peguei, Se manda daqui fica nítida a pronúncia semitônica dos pronomes. Não é outra a razão do conhecido hábito brasileiro de "começar frase com pronome átono", fato que em épocas não tão remotas causava horror aos gramáticos puristas. (AZEREDO, 2008, p. 259)

A adoção da ênclise na colocação pronominal, por consequência, é analisada pelo autor como traço de formalismo e pode revelar alto grau de monitoramento ou 
artificialismo no discurso. Logo, esta seria condicionada por fatores sóciocomunicativos, não por gramaticalidade ${ }^{6}$.

Quanto ao critério sintático, três aspectos devem ser considerados:

a) Se o pronome átono conecta-se a uma forma verbal simples ou a uma locução verbal;

b) Se o pronome funciona como complemento ou se participa de uma construção indeterminadora do agente/sujeito (forma se);

c) Se há particularidades sintagmáticas ou morfossintáticas que impõem um posicionamento único do pronome.

Com base nesses critérios, Azeredo (2008) admite a próclise como a posição mais comum em lexias verbais simples nas variedades de português faladas no Brasil. Entretanto, o autor detalha outras seis regras para a colocação pronominal. São elas:

a) A próclise constitui uso padrão na variedade culta quando a palavra que o procede imediatamente é um advérbio ou pronome de significação negativa:

b) Se a palavra que precede imediatamente o verbo é um conectivo de subordinação, a colocação preferida é a próclise, especialmente se o verbo encontra-se no modo subjuntivo.

c) As formas lo/la/los/las, variantes o/a/os/as, são necessariamente enclíticas ao infinitivo e às formas terminadas em $-\mathrm{se}-\mathrm{z}$.

d) As formas no/na/nos/nas, também variantes de o/a/os/as, são necessariamente enclíticas às formas verbais terminadas por vogal ou ditongo nasal.

e) Quando a forma verbal está no futuro do presente ou do pretérito e seu sujeito está explícito, coloca-se o pronome em próclise.

f) A regra (e), que já está sujeita aos princípios do registro formal, apresenta variante em um registro ultra-formal. Trata-se da mesóclise.

\footnotetext{
${ }^{6}$ Contudo, Azeredo (2008, p. 259) define como irreal a construção “o convidei”, uma vez que as formas átonas a/o/as/os não pertencem ao registro de língua no qual a próclise dos pronomes em começo de frase é praticada.
} 


\section{Castilho (2010)}

Como veremos, A Nova Gramática do Português Brasileiro, de Ataliba T. de Castilho, tem um caráter inovador, que se manifesta também no estudo dos pronomes em PB.

Para Castilho (2010), os pronomes pessoais são bastante suscetíveis a mudanças, o que se evidencia, sobretudo, em sua modalidade falada, com fortes consequências na estrutura sintática da língua.

Conforme Castilho (2010), o PB atual apresenta o seguinte quadro de pronomes pessoais:

\begin{tabular}{|c|c|c|c|c|}
\hline \multirow[t]{2}{*}{ PESSOA } & \multicolumn{2}{|c|}{ PB FORMAL } & \multicolumn{2}{|c|}{ PB INFORMAL } \\
\hline & Sujeito & Complemento & Sujeito & Complemento \\
\hline $1^{\mathrm{a}}$ pessoa sg. & $E u$ & Me, mim, comigo & Eu, a gente & $\begin{array}{l}\text { Eu, me, mim, Prep } \\
+e u, \text { mim }\end{array}$ \\
\hline $2^{\mathrm{a}}$ pessoa sg. & $\begin{array}{l}\text { Tu, você, o senhor, } \\
\text { a senhora }\end{array}$ & $\begin{array}{l}\text { Te, ti, contigo, } \\
\text { Prep +o senhor, } \\
\text { com a senhora }\end{array}$ & Vocêlocê/tu & $\begin{array}{l}\text { Vocêlocê/cêe }{ }^{7}, t e, t i, \\
\text { Prep + vocêlocê } \\
(=\text { docê, cocê })\end{array}$ \\
\hline $3^{\mathrm{a}}$ pessoa sg. & Ele, ela & $\begin{array}{l}\text { Ola, lhe, se, si, } \\
\text { consigo }\end{array}$ & Elelei, ela & $\begin{array}{l}\text { Ele, ela, lhe, Prep }+ \\
\text { ele, ela }\end{array}$ \\
\hline $1^{\mathrm{a}}$ pessoa pl. & Nós & Nos, conosco & A gente & $\begin{array}{l}E \text { gente, Prep }+a \\
\text { gente }\end{array}$ \\
\hline $2^{\mathrm{a}}$ pessoa $\mathrm{pl}$ & $\begin{array}{l}\text { Vós, os senhores, } \\
\text { as senhoras }\end{array}$ & $\begin{array}{l}\text { Vos, convosco, } \\
\text { Prep }+ \text { os } \\
\text { senhores, } \\
\text { senhoras }\end{array}$ & Vocês/ocês/cês & $\begin{array}{l}\text { Vocês/ocês/cês, } \\
\text { Prep + vocês/ocês }\end{array}$ \\
\hline $3^{\mathrm{a}}$ pessoa pl. & Eles, elas & $\begin{array}{l}\text { Os/as, lhes, se, si, } \\
\text { consigo }\end{array}$ & Eles/eis, elas & $\begin{array}{l}\text { Eles/eis, elas, Prep } \\
+ \text { eles/eis, elas }\end{array}$ \\
\hline
\end{tabular}

Quadro 4: Pronomes pessoais em Castilho (2010)

Em sua gramática, Castilho (2010) analisa detalhadamente a reorganização do quadro dos pronomes pessoais em PB, apontando três processos: (i) criação,

\footnotetext{
${ }^{7}$ Embora apresente as formas cê/cês como complementos não preposicionados no quadro acima, Castilho (2010: 477) afirma que essas formas contraídas, bem como a forma ei, não podem funcionar como complementos em PB.
} 
substituição e alteração de formas pronominais; (ii) perdas e ganhos no quadro dos reflexivos; e (iii) transformação progressiva dos pronomes pessoais em morfemas prefixais de pessoa. A seguir, expomos pontos significativos dos processos (i) e (iii):

(i) Criação, substituição e alteração de formas pronominais:

1. Primeira pessoa:

A forma nós tem sido substituída pelo sintagma nominal a gente, como se percebe nos exemplos abaixo, retirados de Castilho (2010: 478):

(1) A gente não está sabendo bem como sair desta.

(2) Nós rimos muito ontem à noite, e aí a gente começamos a se entender.

2. Segunda pessoa:

Na segunda pessoa do singular, tu tem sido substituído por você, forma que surgiu por alterações fonológicas na expressão de tratamento Vossa Mercê. Conforme o autor, em algumas regiões brasileiras, o tratamento $t u$ continua vigente. Nessas regiões, você indicaria distanciamento. Usa-se também a forma o senhor, designada para tratamento cerimonioso.

\section{Terceira pessoa:}

Quanto às mudanças no quadro de pronomes de terceira pessoa, Castilho (2010) destaca: (i) a alteração nas formas ele/eles para ei/eis, quando na função de sujeito; (ii) o uso de eleleles também como objeto direto; (iii) o desaparecimento das formas $o$ e seus alomorfes; (iv) a mudança da forma lhe para li, que funciona como objeto direto; e (v) a grande alteração no quadro de reflexivos.

Para Castilho (2010), a perda do clítico o é acompanhada de dois ganhos: ele e lhe, que antes funcionavam como sujeito e objeto indireto, respectivamente, e agora assumem também a função acusativa.

(iii) Transformação progressiva dos pronomes pessoais em morfemas prefixais de pessoa 
Conforme o autor, há uma transformação progressiva dos pronomes pessoais em morfemas prefixais de pessoa, o que já havia sido insinuado "nas entrelinhas do ensaio de Câmara Jr. sobre o clítico o" (CASTILHO, 2010, p.482). A fim de demonstrar essa postulação, Castilho (2010) apresenta o seguinte quadro:

\begin{tabular}{|c|c|c|c|}
\hline Pessoas & $\begin{array}{c}\text { Prefixos em função de } \\
\text { sujeito no PB não } \\
\text { padrão }\end{array}$ & $\begin{array}{c}\text { Prefixos em função de } \\
\text { complemento no } P B \\
\text { não padrão }\end{array}$ & $\begin{array}{l}\text { Sufixos em função de } \\
\text { sujeito no PB padrão }\end{array}$ \\
\hline P1 & $\begin{array}{l}\{\mathrm{e}-\}: \text { Eu vou }>E v \hat{o} \\
\{\text { noi- }\}: \text { Nós vamos }> \\
\text { noivamo }\end{array}$ & $\begin{array}{l}\text { Me encontrou } \\
\text { Mincontrô }\end{array}$ & $\begin{array}{l}\{-0\}: f o \\
\{-\operatorname{mos}\}\end{array}$ \\
\hline P2 & $\begin{array}{l}\{\text { ce- }\} \text { : Você vai }>\text { Cevai } \\
\{\text { ceis- }\} \text { : Vocês vão > } \\
\text { Ceisvão }\end{array}$ & $\begin{array}{l}\text { Te encontrou } \\
\text { Tincontrô }\end{array}$ & $\begin{array}{l}\{-\mathrm{s}\}: \text { falas } \\
\{-\mathrm{ys}\}: \text { falais }\end{array}$ \\
\hline P3 & $\begin{array}{l}\{\text { ey-\}: Ele vai }>\text { Eivai } \\
\{\text { eys-/es-\}: Eles vão> } \\
\text { eisvão/esvão }\end{array}$ & $\begin{array}{l}\text { Se encontrou > }> \\
\text { Sincontrô }\end{array}$ & $\begin{array}{l}\{-\varnothing\}: \text { fala } \\
\{- \text { ãw/-i }\}: \text { falam/falim }\end{array}$ \\
\hline
\end{tabular}

Quadro 5: pronomes, clíticos e afixos

No que diz respeito à colocação pronominal em PB, Castilho (2010) assinala a preponderância da próclise, diferentemente do que ocorre no português europeu (PE):

Focalizando os tempos modernos, vê-se que o português europeu é predominantemente enclítico, ao passo que o PB é predominantemente proclítico (CASTILHO, 2010, p.484).

\section{Perini (2010)}

A Gramática do português brasileiro, de Mário Perini, é uma gramática descritiva, cujo objeto de análise é o "português falado do Brasil" (PERINI, 2010, p. 19), em oposição à norma culta escrita do português:

A língua que falamos (nós todos, operários, professores, mecânicos, médicos e manicures) é bastante diferente da língua que escrevemos (isto é, aqueles dentre nós que têm a formação necessária para a tarefa de escrever). (...) Uns momentos de reflexão devem deixar bem claro que as duas variedades existem, vão continuar a existir e, 
principalmente, não podem ser trocadas (...) Há muito mais do que apenas duas [variedades do português]; estou simplificando as coisas. Mas creio que as diversas variedades faladas, em conjunto, se opõem nitidamente à variedade padrão escrita, o que nos autoriza a falar do português falado do Brasil como uma entidade linguística razoavelmente coerente. (PERINI, 2010, p.19) [Grifos do autor]

Segundo Perini (2010), "os pronomes pessoais têm um comportamento gramatical peculiar e precisam ser estudados separadamente" (PERINI, 2010, p.115). Por esta razão, a Gramática do português brasileiro reserva um capítulo apenas para o estudo das formas oblíquas e colocação pronominal.

Abaixo, a proposta de Perini (2010) para o quadro de pronomes em PB:

\begin{tabular}{|l|l|}
\hline Forma reta & Forma oblíqua \\
\hline Eu & Me, mim, -migo \\
Você, (tu) & Te, (-tigo) ${ }^{*},($ ti), (lhe) \\
Ele, ela & Nos, -nosco \\
Nós & - \\
Vocês & - \\
Eles, elas & Se \\
[reflexivo] & Quadro 6: Pronomes pessoais em Perini (2010) \\
\hline \multicolumn{2}{|c|}{}
\end{tabular}

*As formas em parênteses, segundo o autor, são de uso restrito, sendo correntes em parte do território brasileiro.

Perini (2010) observa que os pronomes que não têm formas oblíquas (ele/ela, vocês, eles/elas) são usados em todas as funções sintáticas. Os pronomes que mudam de forma, ou seja, assumem forma oblíqua, obedecem à seguinte regra: são usadas as formas retas em função de sujeito, enquanto as formas me, te, lhe e se são usadas em função de objeto. Você, como destaca o autor, tem a forma oblíqua te, utilizada em concorrência com a forma reta, "de maneira que se pode dizer eu te amo ou eu amo você, indiferentemente" (PERINI, 2010, p. 116, grifos do autor). Já o plural vocês não tem forma oblíqua. 
Sobre a colocação pronominal em PB, Perini (2010) destaca que "o pronome oblíquo (sem preposição) se posiciona sempre antes do verbo principal da oração" (PERINI, 2010, p.119). Ou seja, para Perini (2010), a próclise é a regra geral em PB.

\section{Considerações Finais}

Nosso trabalho está inserido em um projeto que pretende descrever o atual quadro de pronomes e as regras de colocação pronominal em PB. Por isso, investigamos esses pontos em cinco gramáticas, relativamente modernas, que diziam analisar dados do português falado ou escrito no Brasil. Algumas dessas gramáticas (Moura Neves, 2000 e Luft, 1987) permaneceram mais fiéis à tradição gramatical. Azeredo (2008), que pretendia apresentar uma proposta equilibrada entre a tradição e as pesquisas linguísticas, teve êxito em sua proposta. Perini (2010) e Castilho (2010) trouxeram as propostas mais inovadoras e se comprometeram em descrever o quadro pronominal usado no Brasil. Esses autores também rejeitaram categoricamente a ênclise como uma regra geral de colocação pronominal em PB.

Este artigo teve o objetivo de ampliar o estudo de Fonseca (2008); servir de base à nossa investigação sobre pronomes e colocação pronominal em $\mathrm{PB}$, além de sistematizar as informações e análises em gramáticas do PB, a fim de auxiliar futuros pesquisadores que pretendam se debruçar sobre o tema.

\section{Referências Bibliográficas}

AZEREDO, J. C. Gramática Houaiss da língua portuguesa. São Paulo: Publifolha, 2008 .

CASTILHO, A. T. Nova gramática do português brasileiro. São Paulo: Contexto, 2010.

FONSECA, C. J. A ordem dos clíticos em lexias verbais simples: uma análise das gramáticas tradicionais. Soletras, ano VIII, n 15. São Gonçalo: UERJ, jan./jun. 2008.

LUFT, C. P. Moderna gramática brasileira. Edição revista e atualizada por M. Módulo e M. E. Viaro. São Paulo: Globo, 2002. 
MOURA NEVES, M. H. Gramática de usos do português. São Paulo: UNESP, 2000.

OTHERO, G. A.; FINKENAUER, L.; WINK, C. O. Colocação Pronominal em português brasileiro. Seminários em Teoria e Análise Linguística. Porto Alegre, UFRGS, 2011.

PERINI, M. A. Gramática do português brasileiro. São Paulo: Parábola, 2010.

VIEIRA, S. R. Colocação pronominal nas variedades européia, brasileira e moçambicana: para a definição da natureza do clítico em português. Tese (Doutorado). UFRJ, Rio de Janeiro, 2002.

VIEIRA, S. R. A ordem dos clíticos em lexias verbais simples nas variedades brasileira, européia e moçambicana do português. Anais do $5^{\circ}$ Encontro do Celsul, Curitiba, 2003.

Artigo recebido em: 31.03 .2012

Artigo aprovado em: 14.06.2012

(C) Caroline Ozório Wink, Letícia Finkenauer, Gabriel de Ávila Othero 